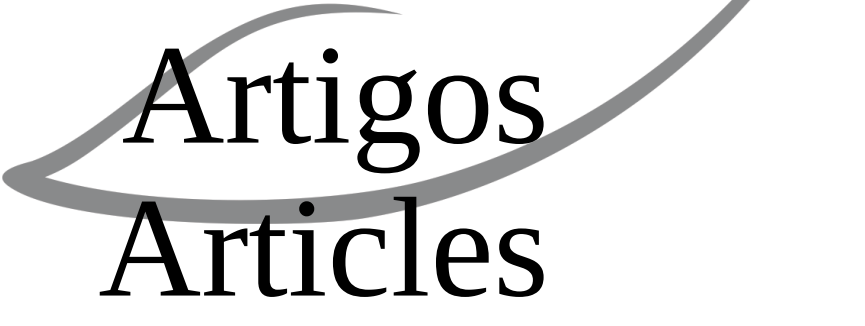





\title{
EXIGÊNCIA CONCEPTUAL DO TRABALHO PRÁTICO NOS EXAMES NACIONAIS: UMA ABORDAGEM METODOLÓGICA
}

\author{
CONCEPTUAL DEMAND OF PRACTICAL WORK IN NATIONAL EXAMS: \\ A METHODOLOGICAL APPROACH
}

\section{LA EXIGENCIA CONCEPTUAL DEL TRABAJO PRÁCTICO EN LOS EXÁMENES NACIONALES: UN ENFOQUE METODOLÓGICO}

\author{
Sílvia Ferreira* \\ Ana Maria Morais**
}

\begin{abstract}
Resumo: O estudo foi realizado no contexto do sistema educativo português, onde os exames nacionais assumem as funções de certificação e de seleção no acesso ao ensino superior. O artigo está centrado no nível de complexidade do trabalho prático na avaliação externa das ciências (i.e. exames nacionais) do ensino secundário. O nível de complexidade foi avaliado utilizando o conceito nível de exigência conceptual, que incluiu a complexidade dos conhecimentos científicos e das capacidades cognitivas e o grau de relação entre teoria e prática. O estudo analisa ainda a relação entre o currículo e os exames, para estudar processos de recontextualização ocorridos na construção dos exames. Está fundamentado psicológica e sociologicamente, em particular na teoria do discurso pedagógico de Bernstein. Usou-se uma metodologia mista. Na análise dos exames nacionais, apenas foram consideradas as questões que apelavam à avaliação do trabalho prático, ou seja, as questões que mobilizavam capacidades de processos científicos. Os resultados mostram que o trabalho prático está deficientemente representado nos exames, quer em quantidade quer no nível de exigência conceptual, evidenciando uma recontextualização do currículo no sentido de baixar o seu já baixo nível. Os conhecimentos a serem avaliados são o único aspecto deixado explícito aos professores. Exploram-se as consequências desses resultados em termos de aprendizagem científica.
\end{abstract}

Palavras-chave: Trabalho prático. Capacidades de processos científicos. Exigência conceptual. Avaliação externa das ciências.

Abstract: This study was conducted in the context of the Portuguese educational system, where national exams have the functions of certification and selection for the access to higher education.

\footnotetext{
* Doutoranda em Didática das Ciências no Instituto de Educação da Universidade de Lisboa e professora de Biologia e Geologia do ensino básico e do ensino secundário. Correio eletrônico: <silviacrferreira@gmail.com>.

** Doutora em Sociologia da Educação pelo Instituto de Educação da Universidade de Londres. Professora catedrática aposentada e coordenadora do Grupo ESSA (Estudos Sociológicos da Sala de Aula) do Instituto de Educação da Universidade de Lisboa. Correio eletrônico:<ammorais@ie.ul.pt>.
} 
The paper addresses the issue of the level of complexity of practical work in science external assessment (i.e. national exams) for high school. The level of complexity is seen in terms of the level of conceptual demand as given by the complexity of scientific knowledge and cognitive skills and the degree of relation between theory and practice. This study also intends to analyse the relation between curriculum and exams, by studying recontextualizing processes that may have occurred in the exams construction. The study is psychologically and sociologically grounded, particularly on Bernstein's theory of pedagogic discourse. It makes use of a mixed methodology. The analysis of national exams considered only the questions which focused practical work assessment, i.e. questions that mobilised science process skills. The results show that practical work is poorly represented in exams, both in quantity and level of conceptual demand, showing recontextualization of the curriculum in the direction of lowering the already low level of the curriculum. Knowledge that should be assessed is the only aspect that is clearly explicated to teachers. The consequences of these results in terms of scientific learning are explored.

Keywords: Practical work. Science process skills. Conceptual demand. Science external assessment.

Resumen: El estudio se llevó a cabo en el contexto del sistema educativo portugués, donde los exámenes nacionales asumen las funciones de certificación y de selección en el acceso a la enseñanza superior. El artículo está centrado en el nivel de complexidad del trabajo práctico en la evaluación externa de las ciencias (es decir, los exámenes nacionales) de la enseñanza secundaria. El nivel de complexidad se ha evaluado a partir del nivel de exigencia conceptual, que incluyó la complexidad de los conocimientos científicos y de las capacidades cognitivas y el grado de relación entre teoría y práctica. El estudio analiza aún la relación entre el currículo y los exámenes, para estudiar procesos de recontextualización ocurridos en la construcción de los exámenes. Está fundamentado psicológica y sociológicamente, en particular en la teoría del discurso pedagógico de Bernstein. Se utilizó una metodología mixta. En el análisis de los exámenes nacionales, se consideraron sólo las cuestiones que recurrían a la evaluación del trabajo práctico, es decir, las cuestiones que movilizaban capacidades de procesos científicos. Los resultados muestran que el trabajo práctico está deficientemente representado en los exámenes, ya sea en cantidad o en el nivel de exigencia conceptual, lo que evidencia una recontextualización del currículo en el sentido de bajar su ya bajo nivel. Los conocimientos que se deben evaluar son el único aspecto que han dejado explícito los profesores. Se explotan las consecuencias de estos resultados con fines de aprendizaje científico.

Palabras clave: Trabajo práctico. Capacidades de procesos científicos. Exigencia conceptual. Evaluación externa de las ciencias.

\section{Introdução}

O trabalho prático realizado pelos alunos no contexto de aprendizagem científica vem sendo encarado por muitos investigadores e professores de ciências como um conjunto de atividades essenciais ao processo de ensino-aprendizagem. Contudo, vários estudos apontam para a necessidade de se repensar a natureza e a implementação desse trabalho prático, uma vez que, por exemplo, o desempenho dos alunos nessas atividades geralmente não é avaliado (HOFSTEIN; LUNETTA, 2004; LUNETTA; HOFSTEIN; CLOUGH, 2007). Nesse sentido, no atual contexto do sistema educativo português, 
a componente prática das disciplinas de ciências do ensino secundário ${ }^{1}$ assumiu uma importância significativa na avaliação dos alunos, com "um peso mínimo de 30\% no cálculo da classificação a atribuir em cada momento formal de avaliação" (Portaria n. ${ }^{\circ}$ $1322 / 2007$, ponto 6 , artigo $9^{\circ}$ ).

O principal objetivo deste artigo é divulgar uma abordagem metodológica que pode ser utilizada para apreciar o nível de complexidade do trabalho prático na avaliação externa das ciências, isto é, nos exames nacionais. Para tal, apresenta-se um estudo realizado no contexto do sistema educativo português, onde os exames nacionais assumem as funções de certificação e de seleção no acesso ao ensino superior. ${ }^{2}$ A avaliação externa do trabalho prático do ensino secundário está incluída num exame teórico nacional que também avalia outras dimensões do ensino das ciências. De facto, com evidentes limitações, várias capacidades de processos científicos podem ser avaliadas com recurso a exames teóricos (BRITTON; SCHNEIDER, 2007; HARLEN, 1999; WILSON; BERTENTHAL, 2006). Os exames nacionais e os respetivos critérios de correção têm sido produzidos pelo Gabinete de Avaliação Educacional (GAVE), integrado na administração direta do Estado, no âmbito do Ministério da Educação e Ciência (MEC).

$\mathrm{O}$ estudo que se apresenta neste artigo integra uma investigação mais ampla e

1. Em Portugal, o ensino básico inicia-se aos seis anos de idade e inclui três níveis, compostos no total por 9 anos de escolaridade. Segue-se o ensino secundário, que é composto por três anos (15-17 anos de idade). O ensino básico e o ensino secundário em Portugal são equivalentes, respetivamente, ao Ensino Fundamental e ao Ensino Médio no Brasil.

2. Ao contrário do Exame Nacional do Ensino Médio realizado no Brasil, em Portugal os exames nacionais são obrigatórios para todos os alunos em cursos de prosseguimento de estudos e têm um peso significativo no acesso ao ensino superior. dá continuidade a estudos anteriores realizados pelo grupo ESSA ${ }^{3}$ (MORAIS; NEVES, 2001, 2011). A investigação centra-se na disciplina de Biologia e Geologia ${ }^{4}$ e pretende investigar questões relacionadas com as orientações dadas pelo MEC relativas aos contextos de transmissão e avaliação do trabalho prático nesta disciplina e à sua recontextualização no que se refere às concepções e às práticas dos professores. Com base nessa análise, será possível explorar em que medida essas diretivas do MEC permitem elevar o nível da educação científica dos alunos portugueses, por meio da ênfase proposta no trabalho prático, nomeadamente laboratorial investigativo, e ainda sobre o seu nível de exigência conceptual. Foi possível avaliar esse nível de exigência conceptual a partir da análise conjunta da complexidade dos conhecimentos científicos e das capacidades cognitivas e da relação entre conhecimentos da disciplina (ver enquadramento teórico).

O estudo centra-se, em particular, na análise da mensagem das fichas de avaliação externa (exames nacionais e testes intermédios) de Biologia e Geologia e pretende responder ao seguinte problema: Qual é a mensagem transmitida pelo discurso pedagógico oficial veiculado nas fichas de avaliação externa de Biologia e Geologia do ensino secundário quanto ao estatuto e ao nível de exigência conceptual do trabalho prático $e$ em que medida essa mensagem representa

3. O Grupo ESSA - Estudos Sociológicos na Sala de Aula - é um grupo de investigação do Instituto de Educação da Universidade de Lisboa: <http://essa.ie.ul.pt>.

4. Em Portugal (um país com um sistema educativo centralizado), o plano curricular do ensino secundário contém disciplinas de ciências para os alunos que pretendem seguir percursos académicos nessas áreas. A disciplina bianual de Biologia e Geologia está incluída nesse grupo de disciplinas. É de salientar que em Portugal, tal como em outros países latinos, Biologia e Geologia, apesar de epistemologicamente distintas, tradicionalmente têm feito parte da mesma disciplina. 
uma recontextualização da mensagem veiculada no currículo? De acordo com esse problema, estabeleceram-se as seguintes questões de investigação: (1) Qual o estatuto do trabalho prático nas fichas de avaliação externa?; (2) Qual o nível de complexidade dos conhecimentos científicos e das capacidades cognitivas?; (3) Qual a natureza da relação entre teoria e prática?; (4) Em que medida o MEC torna essa mensagem explícita aos professores?; e (5) Qual a extensão e qual o sentido de recontextualização do Discurso Pedagógico Oficial (DPO) das fichas de avaliação externa em relação ao DPO do currículo? $\mathrm{O}$ estudo discute ainda em que medida os processos de recontextualização eventualmente ocorridos na construção das fichas de avaliação externa poderão influenciar a prática dos professores e a aprendizagem científica dos alunos.

\section{Enquadramento teórico}

O quadro teórico em que o estudo se baseia está relacionado com teorias e conceitos das áreas da psicologia (e.g. MARZANO; KENDALL, 2007, 2008) e da sociologia, com particular destaque para a teoria do discurso pedagógico de Bernstein (1990; 2000). Foram ainda consideradas algumas conceptualizações atuais sobre o ensino das ciências, nomeadamente quanto ao trabalho prático (e.g. HODSON, 1993; LUNETTA et al., 2007).

A teoria de Bernstein (1990, 2000) possui um forte poder explicativo, de diagnóstico e de transferência, sendo caracterizada por uma linguagem de descrição que permite analisar, descrever, comparar e diferenciar acontecimentos de diferentes contextos. De acordo com essa teoria, o currículo e os exames nacionais de uma determinada disciplina integram o DPO produzido no âmbito do Ministério da Educação, no campo de recontextualização oficial. Tal discurso é resultado da recontextualização do Discurso Regulador Geral (DRG), produzido no campo do Estado, e é influenciado pelo campo da economia, pelo campo do controlo simbólico e ainda pelo campo internacional.

O discurso pedagógico veicula, como mensagem sociológica, determinadas relações de poder e controlo entre as seguintes categorias: espaços (por exemplo, espaço professor-aluno), discursos (por exemplo, intradisciplinar e interdisciplinar) e sujeitos (por exemplo, Ministério da Educaçãoprofessor e professor-aluno). Para analisar tais relações de poder e controlo, são usados os conceitos de classificação e enquadramento, respetivamente (BERNSTEIN, 1990). A classificação diz respeito ao estabelecimento de fronteiras mais ou menos acentuadas entre as categorias anteriormente mencionadas. Ela será tanto mais forte quanto mais nítida for a separação existente entre as categorias. $\mathrm{O}$ enquadramento está relacionado com as relações sociais que se estabelecem entre as categorias consideradas, ou seja, com a forma de comunicação que se estabelecerá entre elas. Considerando a relação entre o Ministério da Educação (agentes oficiais) e os professores (agentes pedagógicos), a qual constitui o objeto de análise neste estudo, em particular, existem fronteiras hierarquicamente nítidas: os agentes oficiais têm um estatuto mais elevado que os agentes pedagógicos, existindo assim uma classificação forte. Em relação ao enquadramento, este é forte quando a categoria de maior estatuto assume o controlo da relação e fraco quando a categoria de menor estatuto partilha esse controlo.

Segundo Bernstein (1990), a relação entre sujeitos é regulada por dois sistemas de regras: regras hierárquicas e regras discursivas. As regras hierárquicas são princípios 
que regulam as normas de conduta social e estão relacionadas com o controlo que os sujeitos em interação podem ter sobre as normas. As regras discursivas dizem respeito às regras relativas à transmissão-aquisição do discurso e são a seleção, a sequência, a ritmagem e os critérios de avaliação. Essas regras estão relacionadas com o controlo que os transmissores e adquiridores podem ter no processo de ensino-aprendizagem. Relativamente aos critérios de avaliação, estes estão relacionados com quem estabelece o texto legítimo a ser apreendido, podendo ser explícitos ou implícitos. Por exemplo, no exame nacional de uma determinada disciplina, as orientações dadas pelo Ministério da Educação aos professores sobre os critérios de avaliação podem ser ou não explícitas. No primeiro caso, existe um controlo do MEC sobre os professores relativo aos critérios que determinam a produção do texto legítimo e, no segundo, existe uma partilha desse controlo entre os dois agentes (MEC e professores).

Os exames nacionais veiculam uma mensagem sociológica que resulta da interação de vários fatores e representa um conjunto de aprendizagens que, por serem consideradas socialmente necessárias num determinado tempo e contexto, devem ser avaliadas. O nível de complexidade de um exame nacional pode ser avaliado pelo seu nível de exigência conceptual.

O conceito de exigência conceptual foi introduzido por Morais (1991) e estava relacionado com a natureza das capacidades cognitivas a serem desenvolvidas pelos alunos. Por exemplo, um baixo nível de exigência conceptual correspondia ao desenvolvimento de capacidades com um baixo nível de abstração (memorização e compreensão de nível simples). Estudos posteriores (e.g. MORAIS; NEVES; PIRES, 2004) passaram a considerar a complexidade das capacidades cognitivas e dos conhecimentos científicos para a caracterização do nível de exigência conceptual. Estes estudos mostraram que o efeito da prática pedagógica pode sobrepor-se ao efeito do nível socioeconómico familiar dos alunos, mesmo quando o aproveitamento dos alunos está relacionado com 0 desenvolvimento de capacidades cognitivas e conhecimentos científicos complexos. Consequentemente, não há necessidade de baixar o nível de exigência conceptual para que todos os alunos sejam bem-sucedidos na escola. O conceito de exigência conceptual evoluiu e passou a incluir três dimensões: a complexidade dos conhecimentos científicos e das capacidades cognitivas e o grau das relações intradisciplinares (e.g. CALADO; NEVES; MORAIS, 2013). A inclusão das relações intradisciplinares esteve relacionada com a importância dessa dimensão para elevar o nível da aprendizagem científica (e.g. MORAIS; NEVES; PIRES, 2004). Esse é o conceito de exigência conceptual usado no presente estudo, realizado no contexto da avaliação do trabalho prático.

De acordo com vários autores (e.g. ABRAHAMS, 2011; HODSON, 1993; LUNETTA et al., 2007), o trabalho prático tem um importante papel no ensino das ciências. Hodson (1993) apresenta o trabalho prático como sendo um conceito abrangente que compreende toda e qualquer atividade em que os alunos desempenhem um papel ativo. Nele são incluídas atividades tão diversificadas como o trabalho de laboratório, o trabalho de campo, os debates e as representações de papéis, as pesquisas de informação na biblioteca ou na internet, a elaboração de modelos e cartazes, a resolução de exercícios e de problemas, entre outras.

Millar, Maréchal e Tiberghien (1999, p.36) delimitam a definição apresentada por Hodson (1993) e referem que o trabalho prático consiste em "todo o tipo de atividades 
de ensino-aprendizagem em ciências que envolve os alunos, em determinado momento, na manipulação e observação de objetos e materiais reais (ou representações diretas, numa simulação ou gravação de vídeo)”. Os autores afirmam que estas atividades podem ser realizadas no laboratório, no exterior ou numa sala de aula. Ao contrário de Hodson, esses autores excluem da definição de trabalho prático atividades, tais como debates e pesquisa de informação. Na mesma linha de pensamento, Lunetta, Hofstein e Clough (2007, p.394) apresentam a seguinte definição de trabalho prático: "experiências de aprendizagem nas quais os alunos interagem com materiais ou com fontes secundárias de dados para observar e compreender o mundo natural”, por exemplo, o estudo de fotografias aéreas para examinar aspetos geográficos terrestres e lunares.

Tendo em consideração as definições apresentadas e no contexto do presente estudo, adotou-se um significado de trabalho prático próximo do defendido por Hodson (1993), mas um pouco mais restritivo, uma vez que necessariamente ele tem de mobilizar capacidades de processos científicos. Assim, trabalho prático será entendido como: todas as atividades de ensino-aprendizagem em ciências em que o aluno esteja ativamente envolvido e que permitam a mobilização de capacidades de processos científicos e de conhecimentos científicos, podendo ser concretizadas com recurso a papel e lápis ou recorrendo à observação e/ou manipulação de materiais.

Inerente a essa definição de trabalho prático está o conceito de capacidades de processos científicos. Estas foram consideradas como formas de pensamento mais diretamente envolvidas na investigação científica, como, por exemplo, a observação, a formulação de problemas e de hipóteses, o controlo de variáveis e a previsão (e.g.
DUSCHL; SCHWEINGRUBER; SHOUSE, 2007; HARLEN, 1999). Assim, as capacidades de processos científicos são capacidades transversais a diferentes atividades práticas.

As capacidades de processos científicos estão incluídas no grupo das capacidades cognitivas que, na sua generalidade, também foram analisadas no estudo que se apresenta. As capacidades cognitivas foram consideradas como processos mentais que podem apresentar diferentes níveis de complexidade, consoante as etapas envolvidas (MARZANO; KENDALL, 2007). O seu nível de complexidade foi avaliado tendo em consideração a taxonomia proposta por Marzano e Kendall (2007, 2008), com quatro níveis para o sistema cognitivo: recuperação, compreensão, análise e utilização do conhecimento. O primeiro nível, a recuperação, envolve a ativação e a transferência de conhecimento da memória permanente para a memória de trabalho e pode incluir, no domínio da informação, os processos de reconhecimento e recordação. O segundo nível, a compreensão, implica a relação entre o conhecimento recentemente experienciado pelo aluno e o conhecimento já existente na sua memória permanente, relativamente a um acontecimento específico, e envolve a integração e a representação simbólica dos aspectos mais importantes de determinado conhecimento. O terceiro nível, a análise, envolve a produção de nova informação que o indivíduo ainda não possui e ocorre sobre o conhecimento que o indivíduo já compreendeu. A análise abrange cinco processos mentais: correspondência, classificação, análise de erros, generalização e especificação. $O$ quarto nível e o mais complexo do sistema cognitivo, a utilização do conhecimento, implica a aplicação de conhecimento em determinadas situações e envolve quatro processos mentais: tomada de decisão, resolução de problemas, experimentação e investigação. 


\section{Metodologia}

Introdução

A análise das fichas de avaliação externa $^{5}$ da disciplina de Biologia e Geologia produzidas pelo GAVE incidiu sobre os exames nacionais realizados entre 2006 e 2011, correspondendo a um total de doze exames. Foram ainda analisados os testes intermédios do $10^{\circ}$ e $11^{\circ}$ anos de escolaridade realizados entre 2008 e 2011 (cinco testes intermédios do $10^{\circ}$ ano e nove testes do $11^{\circ}$ ano). Apesar de apenas os exames nacionais terem as funções de certificação e seleção no acesso ao ensino superior, considerou-se pertinente analisar os testes intermédios, uma vez que estes apresentam a tipologia do exame nacional e, assim, possibilitam "aos alunos a familiarização com o tipo de prova de exame que irão realizar" (GAVE, 2010a).

Ambas as modalidades de fichas de avaliação externa estão organizadas em grupos de questões/itens. Cada um desses grupos de questões tem como suporte informações expressas, por exemplo, em textos, tabelas, gráficos, mapas e/ou esquemas. As fichas incluem questões de seleção, frequentemente de escolha múltipla, e questões de construção (BLACK; WILIAM, 2007; GAVE, 2010b). Como o estudo está centrado na avaliação do trabalho prático, apenas foram consideradas para a análise as questões que apelavam ao trabalho prático. Para operacionalizar tal condição, as questões selecionadas tinham de incluir capacidades de processos científicos. Nos exames nacionais foram selecionadas 38 questões e, nos testes intermédios, 42 questões. Cada uma dessas questões correspondeu a uma unidade de análise e incluiu a respetiva proposta de correção apresentada pelo GAVE. Essa

5. As fichas de avaliação externa estão disponíveis para consulta em <http://www.gave.min-edu.pt $>$. informação permitiu aferir algumas das dimensões em estudo.

A análise centrou-se em dimensões do DPO relacionadas com o que e o como se avalia o trabalho prático no ensino das ciências (Figura 1). A análise de o que incidiu na caracterização do grau de complexidade dos conhecimentos científicos e das capacidades cognitivas que o MEC sugere na avaliação do trabalho prático. A análise de o como incidiu na relação intradisciplinar entre teoria e prática (relação entre discursos) e na relação MEC-professor, quanto à regra discursiva "critérios de avaliação". A relação entre teoria e prática, enquanto relação de poder, foi caracterizada utilizando o conceito de classificação. A relação MEC-professor, na condição de princípio regulador do processo de transmissão-aquisição de o que, foi caracterizada utilizando o conceito de enquadramento. A partir da sua análise, pretendeu-se verificar em que medida o MEC explicita aos professores os conhecimentos e as capacidades cognitivas que são objeto de avaliação no trabalho prático. ${ }^{6}$ Com a análise conjunta de algumas dessas dimensões de $o$ que e de o como se avalia, relativamente ao trabalho prático, foi possível inferir o nível de exigência conceptual do DPO veiculado nas fichas de avaliação externa.

\section{Instrumentos de análise}

Para a caracterização da mensagem subjacente a cada unidade de análise e,

6. Este estudo está centrado na relação MEC-professores e portanto a análise da explicitação do trabalho prático refere-se a essa relação. No entanto, a análise também permitiria obter informações sobre a relação MEC-alunos, mostrando em que medida o texto pretendido nas questões de avaliação do trabalho prático é explícito para o aluno. Neste caso, a análise referir-se-ia apenas ao texto das questões e não às respetivas propostas de correção. 
Figura 1. Esquema representativo das dimensões relacionadas com o que e o como analisadas nas fichas de avaliação externa de Biologia e Geologia.

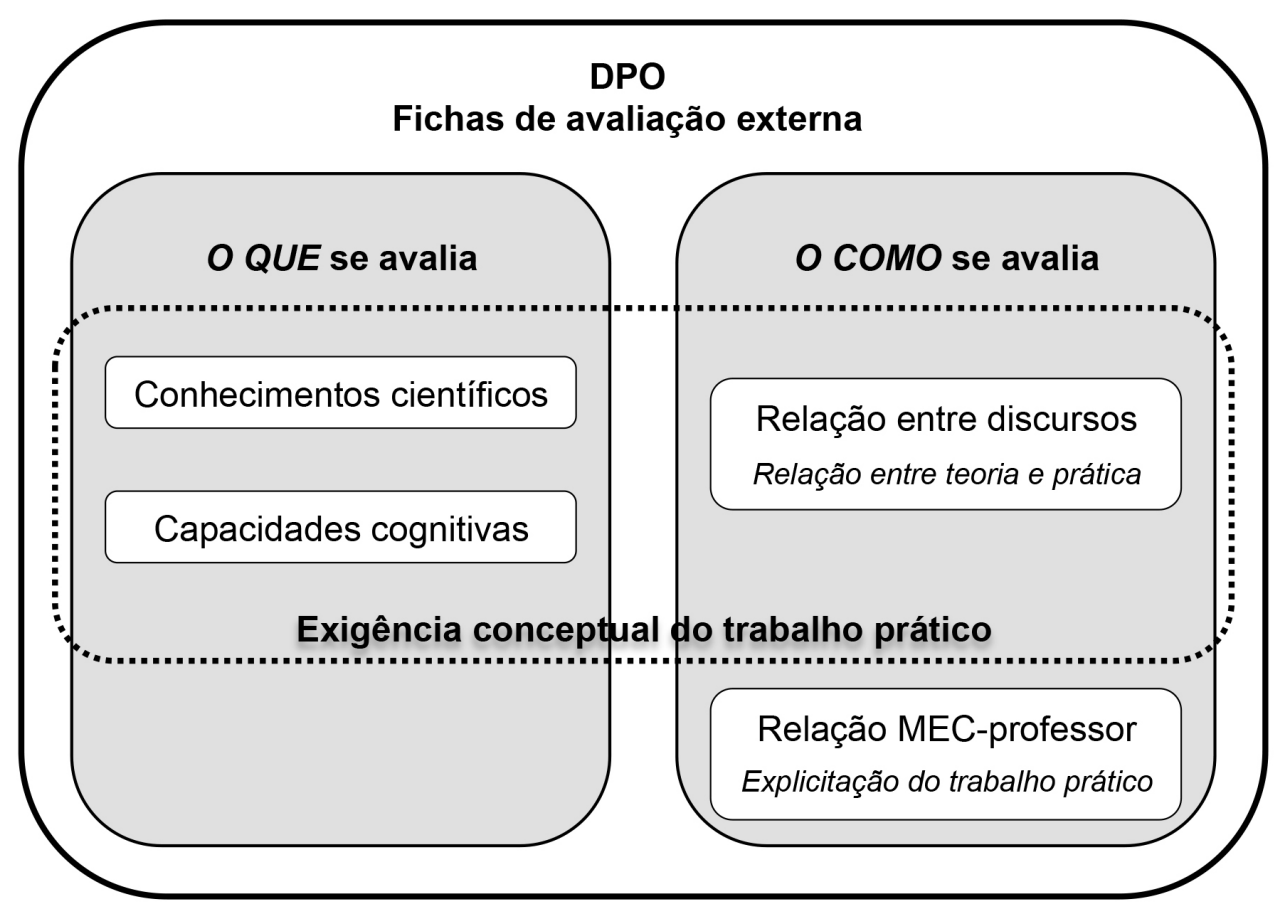

consequentemente, do DPO veiculado nos documentos oficiais da disciplina de Biologia e Geologia (currículo e fichas de avaliação externa) relativo à transmissão e à avaliação do trabalho prático, foram construídos, pilotados e aplicados vários instrumentos para a análise das dimensões de o que e de o como desse discurso. ${ }^{7}$ A conceção e a aplicação dos instrumentos foram validadas por outras duas investigadoras. Os instrumentos basearam-se em modelos/instrumentos construídos em outros estudos sobre a análise de currículos de ciências (e.g. CALADO; NEVES;

7. No âmbito da investigação mais abrangente, de que este estudo faz parte, também se procedeu à análise do DPO veiculado no currículo de Biologia e Geologia quanto à transmissão e à avaliação do trabalho prático (FERREIRA; MORAIS, 2013). Os instrumentos utilizados para ambos os estudos estão disponíveis para consulta em $<$ http://essa.ie.ul.pt/materiais_instrumentos_texto.htm>.
MORAIS, 2013; FERREIRA; MORAIS, 2011).

A construção dos instrumentos seguiu uma orientação metodológica mista (CRESWELL, 2003; CRESWELL; CLARK, 2011; MORAIS; NEVES, 2010), recorrendo a abordagens qualitativas e quantitativas. Por um lado, um quadro teórico de referência esteve na base da construção dos instrumentos (característica de abordagens quantitativas). Por outro, alguns dos descritores usados nos instrumentos foram definidos com base nos dados empíricos (característica de abordagens qualitativas).

De seguida, apresenta-se uma descrição resumida dos instrumentos elaborados e do modo como foram aplicados na análise das questões de trabalho prático das fichas de avaliação externa. Apresentam-se também alguns exemplos da análise dessas questões. 
No que respeita à análise da complexidade dos conhecimentos científicos, presentes nas fichas de avaliação externa da disciplina de Biologia e Geologia, foi construído um instrumento que considerou a distinção entre factos, conceitos simples, conceitos complexos e temas unificadores/ teorias. Considera-se que um facto é constituído a partir "de dados que resultam da observação" (BRANDWEIN; WATSON; BLACKWOOD, 1958, p.111), correspondendo a uma situação muito concreta, resultante de várias observações. Um conceito é uma "construção mental, um grupo de elementos ou atributos partilhados por certos objetos ou eventos" (BRANDWEIN et al., 1980, p.12) e representa uma ideia resultante da associação de vários factos ou de outros conceitos. Os conceitos simples correspondem aos conceitos concretos propostos por Cantu e Herron (1978) e são aqueles que apresentam um nível de abstração baixo, atributos definidores e exemplos observáveis. Os conceitos complexos equivalem aos conceitos abstratos preconizados por Cantu e Herron (1978) e são aqueles que não apresentam exemplos percetíveis ou têm atributos definidores não percetíveis nos exemplos. Os temas unificadores dizem respeito às ideias estruturantes, representando, em ciências, as generalizações acerca do mundo aceites pelos académicos de cada área disciplinar (PELLA; VOELKER, 1968).

O grau de complexidade dos conhecimentos científicos foi, assim, traduzido através de uma escala de quatro graus: (1) factos; (2) conceitos simples; (3) conceitos complexos; e (4) temas unificadores e teorias. Esta dimensão de o que não está relacionada com a natureza dos assuntos científicos a serem apreendidos, mas com o nível conceptual a que esses assuntos podem ser apreendidos. No Quadro 1 , apresenta-se um excerto desse instrumento, para o indicador Avaliação, ${ }^{8}$ e exemplos de unidades de análise que ilustram diferentes graus de complexidade (excertos [1] e [2]).

O instrumento de análise da complexidade das capacidades cognitivas baseou-se na taxonomia proposta por Marzano e Kendall (2007, 2008), que apresenta quatro níveis para o sistema cognitivo: recuperação, compreensão, análise e utilização do conhecimento. No Quadro 2, apresenta-se um excerto deste instrumento, para o indicador Avaliação, e exemplos de unidades de análise das fichas de avaliação externa que representam diferentes graus de complexidade (excertos [3] e [4]).

É importante referir que, no caso do exemplo apresentado para o grau 3 de complexidade das capacidades cognitivas, a capacidade envolvida é a de formular hipóteses (capacidade de processos cognitivos). Essa capacidade teria sido classificada com o grau 4 se tivesse sido solicitado ao aluno que formulasse essa hipótese (questão de construção) e não lhe tivessem sido apresentadas várias alternativas (questão de escolha múltipla). No exemplo apresentado, o aluno tem de possuir regras de realização passiva ${ }^{9}$ para

8. Os instrumentos de análise foram organizados de forma a contemplar as quatro secções principais normalmente presentes em qualquer currículo: conhecimentos, finalidades, orientações metodológicas e avaliação. Essas quatro secções principais foram consideradas como indicadores de análise. No caso específico da análise das fichas de avaliação externa, todas as unidades de análise foram associadas ao indicador Avaliação.

9. Para Bernstein (1990), a produção textual num dado contexto implica que os sujeitos têm de possuir regras de reconhecimento, ou seja, têm de ser capazes de reconhecer o contexto, e têm de possuir também regras de realização, ou seja, - têm, ainda, de ser capazes de produzir o texto adequado àquele contexto. A realização pode ser passiva ou ativa. Os sujeitos têm apenas realização passiva quando são capazes de selecionar os significados mas não são capazes de produzir o texto. Quando o texto é produzido, evidenciam ter realização ativa. 
Quadro 1. Excerto do instrumento de caracterização da complexidade dos conhecimentos científicos

\begin{tabular}{cccc}
\hline Grau 1 & Grau 2 & Grau 3 & Grau 4 \\
\hline $\begin{array}{c}\text { É objeto de avaliação } \\
\text { conhecimento de baixo } \\
\text { nível de complexidade, } \\
\text { como factos. }\end{array}$ & $\begin{array}{c}\text { É objeto de avaliação } \\
\text { conhecimento de nível de } \\
\text { complexidade superior ao } \\
\text { do grau 1, como conceitos } \\
\text { simples. }\end{array}$ & $\begin{array}{c}\text { É objeto de avaliação } \\
\text { conhecimento de nível de } \\
\text { complexidade superior } \\
\text { ao do grau 2, envolvendo } \\
\text { conceitos complexos. }\end{array}$ & $\begin{array}{c}\text { É objeto de avaliação } \\
\text { conhecimento de nível } \\
\text { de complexidade muito } \\
\text { elevado, envolvendo temas } \\
\text { unificadores e/ou teorias. }\end{array}$ \\
\hline
\end{tabular}

Unidades de análise

\begin{tabular}{|c|c|}
\hline & Unidades de análise \\
\hline \multirow{8}{*}{$\begin{array}{l}{[1]} \\
\text { Grau } 2\end{array}$} & GRUPO II \\
\hline & {$[\ldots]$} \\
\hline & $\begin{array}{l}\text { 6. Quando exposta ao sol, a superfície da pelagem de } C \text {. dromedarius pode alcançar temperaturas } \\
\text { superiores a } 70^{\circ} \mathrm{C} \text {, enquanto ao nível da pele a temperatura corporal não ultrapassa os } 40^{\circ} \mathrm{C} \text {. }\end{array}$ \\
\hline & Fxplioue a partir dos dados fornecidos de oue modo a investigacão realizada permitiu relacionar \\
\hline & a adaptação a elevadas temperaturas com os níveis de transpiração apresentados por $C$. dromedarius. \\
\hline & Proposta de correção do MEC - A resposta deve abordar os seguintes tópicos: [...] \\
\hline & (Exame Nacional de 2009, $1^{\text {a }}$ fase) \\
\hline & $\begin{array}{l}\text { Nota das autoras: A questão e a respetiva proposta de correção envolvem conceitos simples relativos } \\
\text { à termorregulação. }\end{array}$ \\
\hline \multirow{7}{*}{$\begin{array}{l}{[2]} \\
\text { Grau } 3\end{array}$} & GRUPO IV \\
\hline & {$[\ldots]$} \\
\hline & $\begin{array}{l}\text { 6. Estudos genéticos em Coccomyxa sugerem que, uma vez estabelecida a relação endossimbiótica } \\
\text { com Ginkgo biloba, a alga se transmitiu de geração em geração. }\end{array}$ \\
\hline & $\begin{array}{l}\text { Explique de que modo os resultados dos estudos efetuados permitem relacionar a transmissão da } \\
\text { relação endossimbiótica, de geração em geração, com a forma como se iniciou esta relação. }\end{array}$ \\
\hline & Proposta de correção do MEC - A resposta deve abordar os seguintes tópicos: [...] \\
\hline & (Exame Nacional de 2009, $2^{\mathrm{a}}$ fase) \\
\hline & $\begin{array}{l}\text { Nota das autoras: A questão e a respetiva proposta de correção envolvem conceitos complexos } \\
\text { relativos à transmissão genética de uma relação endossimbiótica entre uma planta e uma alga verde. } \\
\text { Se a questão apelasse ao estabelecimento de uma relação com o modelo endossimbiótico, o grau de } \\
\text { complexidade aumentaria para o grau } 4 \text {. }\end{array}$ \\
\hline
\end{tabular}

identificar a hipótese, mas não precisa de ter realização ativa porque não tem de ser ele a formulá-la.

Para a análise das relações intradisciplinares entre teoria e prática, o instrumento foi construído com base no grau de relação, que se poderá estabelecer entre a teoria e a prática, veiculado nos documentos oficiais. Para a definição empírica dos quatro graus da escala, partiu-se do significado teórico do conceito de classificação criado por Bernstein (1990, 2000), isto é, da visibilidade da fronteira entre os vários conhecimentos. Desse modo, o valor extremo da classificação mais fraca $\left(\mathrm{C}^{--}\right)$corresponde a uma integração/unificação da teoria e da prática, em que ambas têm igual estatuto, e o valor extremo de classificação mais forte $\left(\mathrm{C}^{++}\right)$indica uma separação muito marcada entre a teoria e a prática. Nesse instrumento, os descritores para cada indicador traduzem a relação entre teoria e prática numa relação entre conhecimento científico declarativo e conhecimento processual. 
Quadro 2. Excerto do instrumento de caracterização da complexidade das capacidades cognitivas

\begin{tabular}{cccc}
\hline Grau 1 & Grau 2 & Grau 3 & Grau 4 \\
\hline São objeto de avaliação & São objeto de avaliação & São objeto de avaliação & São objeto de avaliação ca- \\
capacidades cognitivas & capacidades cognitivas & capacidades cognitivas & pacidades cognitivas com \\
com um baixo nível de & com um nível de complexi- & com um nível de comple- & um nível de complexidade \\
complexidade, envolven- & dade superior ao do grau 1, xidade superior ao do grau & muito elevado, envolvendo \\
do processos cognitivos & envolvendo processos cog- & 2, envolvendo processos & processos cognitivos de uti- \\
de recuperação. & nitivos de compreensão. & cognitivos de análise. & lização do conhecimento. \\
\hline
\end{tabular}

Unidades de análise

\section{GRUPO IV}

[...]

1. Selecione a única opção que permite obter uma afirmação correta.

Com esta experiência pretendeu-se avaliar o efeito...

[3]

(A) da duração do tempo de imersão na solução sobre o potencial hídrico nas células.

Grau 2

(B) do ângulo de curvatura dos cilindros sobre o potencial hídrico nas células.

(C) da concentração do meio externo sobre o potencial hídrico nas células.

(D) do diâmetro inicial dos cilindros sobre o potencial hídrico nas células.

Proposta de correção do MEC - Opção C.

(Teste Intermédio de Maio de 2010, $11^{\circ}$ ano)

Nota das autoras: A capacidade cognitiva envolvida nesta questão é identificar variáveis.

GRUPO IV

$[\ldots]$

2. Selecione a alternativa que completa a frase seguinte, de modo a obter uma afirmação correta. Esta experiência permite testar a hipótese de que...

[4]

(A) ... a inativação da proteína HIF-1 $\alpha$ influencia o crescimento de tumores nos ratos.

[4]

(B) .... proteína HIF-1 $\alpha$ é inativada pelo decréscimo das pressões de oxigénio.

(C) ...a proteína HIF-1 $\alpha$ é mais ativa em células embrionárias do que em células diferenciadas.

(D) .... inativação da proteína HIF-1 $\alpha$ afeta o crescimento de tumores em embriões de ratos.

Proposta de correção do MEC - Opção A.

(Teste Intermédio de Maio de 2008, $11^{\circ}$ ano)

Nota das autoras: A capacidade cognitiva envolvida nesta questão é formular hipóteses.

O conhecimento declarativo corresponde ao conhecimento de termos, factos, conceitos e teorias específicos de uma determinada disciplina (CHI; OHLSSON, 2005; MARZANO; KENDALL, 2007). O conhecimento processual corresponde não só ao conhecimento de como fazer algo, de técnicas e métodos específicos de uma determinada disciplina, mas também ao conhecimento dos processos científicos. No caso da disciplina de Biologia e Geologia, o conhecimento processual envolve, por exemplo, o conhecimento de como formular uma hipótese e o conhecimento do que é uma hipótese. Para Roberts, Gott e Glaesser (2010, p.379), numa ampla investigação em que os autores têm procurado compreender o papel do conhecimento processual no trabalho investigativo e 
a sua relação com o conhecimento declarativo, "o termo conhecimento processual tem sido usado para descrever a compreensão de ideias sobre evidências, as quais sustentam o conhecimento de como proceder".

Para ilustrar o instrumento, o Quadro 3 apresenta um excerto do mesmo para o indicador Avaliação e exemplos de unidades de análise das fichas de avaliação externa (excertos [5] e [6]).

O instrumento de análise da explicitação do trabalho prático (critérios de avaliação) possui uma escala de quatro graus de enquadramento em que, teoricamente, cada grau reflete o controlo detido pelo MEC e dado ao professor. $O$ enquadramento é muito forte $\left(\mathrm{E}^{++}\right)$quando o MEC tem o controlo da relação e, por isso, os descritores empíricos referem-se a situações em que os conhecimentos científicos e as capacidades cognitivas a avaliar nesse trabalho prático estão discriminados nas fichas de avaliação externa. Ao contrário, o enquadramento é muito fraco $\left(\mathrm{E}^{--}\right)$quando é dado controlo ao professor e, por essa razão, os descritores empíricos refletem situações em que os conhecimentos científicos e as capacidades cognitivas a avaliar não estão discriminados na avaliação externa. O Quadro 4 apresenta um excerto do instrumento para o indicador Avaliação e exemplos de unidades de análise das fichas de avaliação externa (excertos [7] e [8]).

Cada uma das unidades de análise das fichas de avaliação externa foi analisada individualmente, do ponto de vista das várias dimensões de o que e de o como em estudo. Para uma melhor clarificação de como a mesma unidade de análise foi avaliada, apresenta-se um exemplo (excerto [9]) ilustrativo da análise efetuada (Quadro 5).

Relativamente ao que do DPO, a questão do exame nacional e a respectiva proposta de correção, apresentadas no excerto [9], apelam a conceitos simples, relativos à relação entre os fatores bióticos e os fatores abióticos, e a capacidades cognitivas simples, que envolvem o processo cognitivo de compreensão, uma vez que é necessário interpretar dados experimentais de baixo nível de complexidade. Perante essa análise, ambas as dimensões foram classificadas com o grau 2. Em relação ao como do DPO, o excerto [9] envolve uma relação entre conhecimento declarativo e conhecimento processual, em que ambos têm igual estatuto, e apresenta orientações explícitas apenas quanto ao conhecimento científico a ser avaliado. Desse modo, a relação entre teoria e prática foi avaliada com o grau $\mathrm{C}^{-}$e a explicitação do trabalho prático com o grau $\mathrm{E}^{+}$.

\section{Análise dos resultados}

Com esta análise pretendia-se caracterizar a mensagem sociológica do DPO expresso nas fichas de avaliação externa da disciplina de Biologia e Geologia do ensino secundário quanto ao nível de exigência conceptual do trabalho prático. A apresentação e a discussão dos resultados desta análise têm em consideração as duas modalidades de fichas de avaliação externa produzidas pelo GAVE para esta disciplina: testes intermédios (TI) e exames nacionais (EN).

O gráfico da Figura 2 evidencia a frequência relativa de questões (unidades de análise) que apelam para a avaliação de trabalho prático e ainda a frequência relativa de questões de escolha múltipla no conjunto de questões de trabalho prático. Analisando-se os dados do gráfico, é possível verificar que as fichas de avaliação externa de Biologia e Geologia atribuem pouca ênfase à avaliação do trabalho prático e, considerando as que fazem essa avaliação, cerca de $76 \%$ o faz com auxílio de itens de escolha múltipla. A análise 
Quadro 3. Excerto do instrumento de caracterização da relação entre teoria e prática

\begin{tabular}{|c|c|c|c|}
\hline$C++$ & $C+$ & $C-$ & $C-$ - \\
\hline $\begin{array}{l}\text { O objeto de avaliação en- } \\
\text { volve apenas o conhecimen- } \\
\text { to científico declarativo. } \\
\text { ou } \\
\text { O objeto de avaliação } \\
\text { envolve apenas o conheci- } \\
\text { mento processual. }\end{array}$ & $\begin{array}{l}\text { O objeto de avaliação en- } \\
\text { volve quer conhecimento } \\
\text { científico declarativo, quer } \\
\text { conhecimento processual, } \\
\text { mas não a relação estabe- } \\
\text { lecida entre eles. }\end{array}$ & $\begin{array}{l}\text { O objeto de avaliação } \\
\text { envolve uma relação entre } \\
\text { conhecimento científico } \\
\text { declarativo e conhecimen- } \\
\text { to processual. Contudo, } \\
\text { a avaliação centra-se em } \\
\text { conhecimento científico } \\
\text { declarativo. }\end{array}$ & $\begin{array}{l}\text { O objeto de avaliação } \\
\text { envolve uma relação entre } \\
\text { conhecimento científico } \\
\text { declarativo e conheci- } \\
\text { mento processual. Nesta } \\
\text { relação, a teoria e a prática } \\
\text { têm igual estatuto. }\end{array}$ \\
\hline
\end{tabular}

Unidades de análise

\section{GRUPO IV}

[...]

4. Selecione a única alternativa que permite obter uma afirmação correta.

A elevada capacidade energética do colibri, que lhe permite fazer o percurso migratório, é apoiada pelos dados do gráfico da Figura 2, uma vez que...

[5] (A) a taxa metabólica varia na razão direta da massa corporal.

C++ (B) a uma pequena massa corporal corresponde uma baixa taxa metabólica.

( $2^{\mathrm{a}}$ parte) (C) a taxa metabólica varia na razão inversa da massa corporal.

(D) a uma grande massa corporal corresponde uma elevada taxa metabólica.

Proposta de correção do $M E C$ - Opção C.

(Teste Intermédio de Maio de 2009, $10^{\circ}$ ano)

Nota das autoras: O gráfico da Figura 2 mostra a relação entre a taxa metabólica basal e a massa corporal de alguns colibris. Para responder à questão, é necessária apenas a interpretação dos dados expressos no gráfico (conhecimento processual).

\section{GRUPO IV}

$[\ldots]$

2. Selecione a única opção que permite obter uma afirmação correta.

Com base nos resultados experimentais descritos, pode afirmar-se que...

(A) a pressão osmótica da solução de 0,5 molar é superior à pressão osmótica do meio intracelular.

(B) a pressão de turgescência verificada nas células de batata aumenta para concentrações superiores a 0,3 molar.

[6] (C) a perda de água pelas células de batata, quando colocadas na solução de 0,1 molar, é maior do C-- que quando colocadas na solução de 0,4 molar.

(D) a redução da pressão de turgescência nas células dos cilindros conduz ao aumento da elasticidade dos tecidos.

Proposta de correção do $M E C$ - Opção A.

(Teste Intermédio de Maio de 2010, $11^{\circ}$ ano)

Nota das autoras: Para responder à questão, é necessário interpretar os resultados experimentais expressos no gráfico. É ainda necessário relacionar esse conhecimento processual com o conhecimento declarativo relativo ao processo de osmose. 
Quadro 4. Excerto do instrumento de caracterização da explicitação do trabalho prático

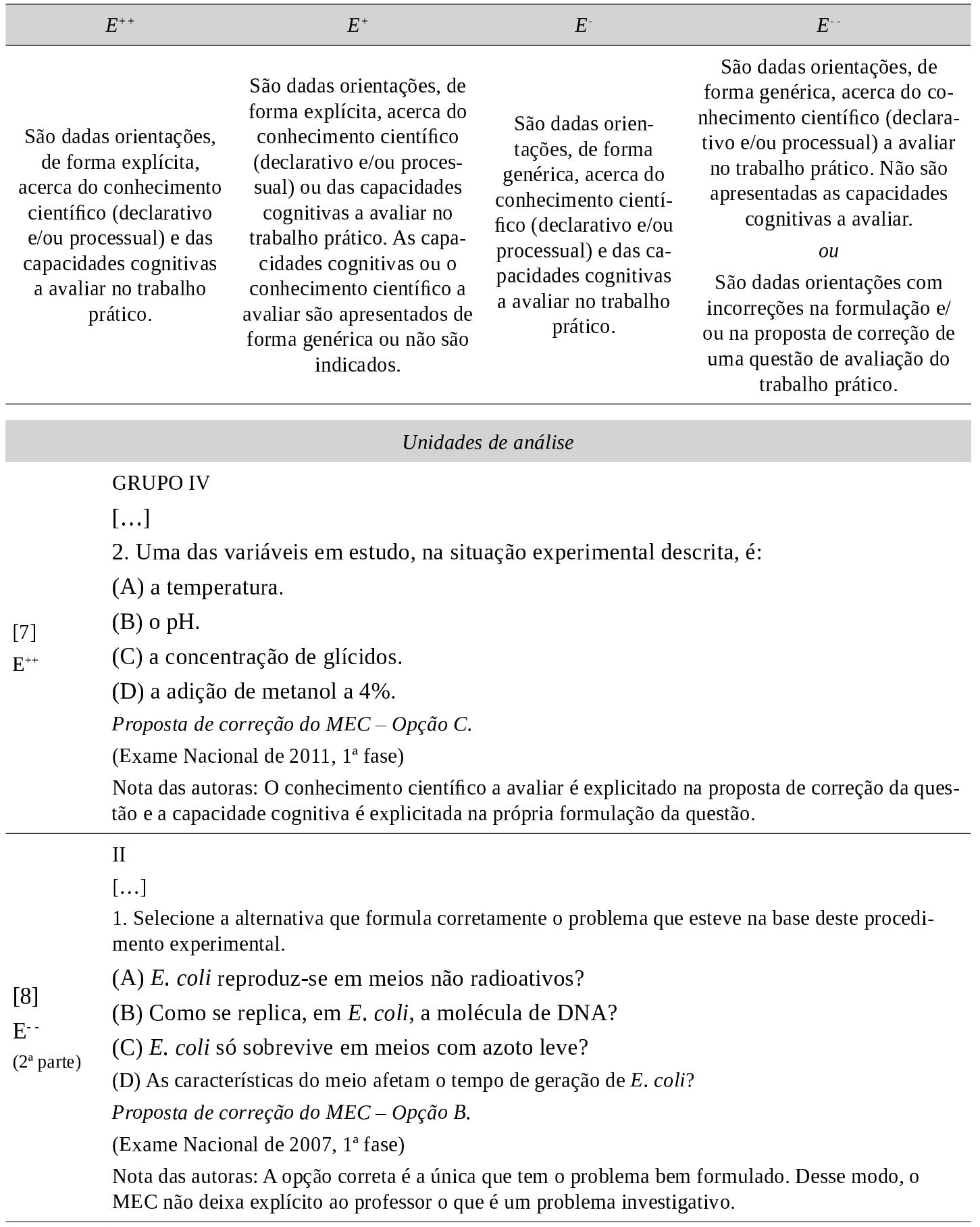


Quadro 5.

\section{GRUPO II}

7. Os fatores que determinam a eclosão dos ovos de dormência têm sido objeto de vários trabalhos de investigação. Num trabalho experimental, produziram-se, em laboratório, ovos de dormência de uma população de um rotífero de água doce, Brachionus calyciflorus. Numa primeira experiência, os ovos foram mantidos em meios com diferentes concentrações dos principais sais existentes no ambiente aquático.

[... gráfico da Figura 4 ...] Na segunda experiência, realizada em câmaras de germinação, os ovos foram mantidos a diferentes temperaturas durante cinco dias, sendo nula a taxa de eclosão no primeiro dia. [... gráfico da Figura 5 ...]

[9] Explique em que medida os resultados do trabalho experimental descrito podem ser conclusivos em relação aos efeitos da salinidade e da temperatura na taxa de eclosão dos ovos de dormência da população de Brachionus calyciflorus.

Proposta de correção do $\mathrm{MEC}$ - A resposta deve abordar os seguintes tópicos: [...]

- os resultados do trabalho experimental descrito permitem concluir que as variações de temperatura influenciam significativamente a taxa de eclosão dos ovos de dormência, enquanto as variações de salinidade do meio têm pouca influência na taxa de eclosão.

(Exame Nacional de 2010, $1^{\text {a }}$ fase)

das fichas de avaliação externa também evidenciou que a maioria das questões de avaliação de trabalho prático está relacionada com a componente de Biologia do currículo da disciplina (aproximadamente $84 \%$ do total de questões). Verificou-se também que os exames nacionais realizados em 2008 e em 2009 são os que apresentam uma menor percentagem de questões de trabalho prático. É importante salientar que foi a partir do ano letivo 2007/2008, pela publicação da Portaria n. ${ }^{\circ} 1322 / 2007$, que a componente prática na disciplina de Biologia e Geologia passou a assumir um peso mínimo de 30\% na avaliação dos alunos. Seria de se esperar que os exames nacionais, pelo menos a partir desse momento, valorizassem a avaliação do trabalho prático e lhe atribuíssem um peso mínimo de 30\%.

Os resultados relativos a cada uma das dimensões relacionadas com o que (conhecimentos científicos e capacidades cognitivas) e o como (relação entre teoria e prática e explicitação do trabalho prático) se avalia, quanto ao trabalho prático, encontram-se expressos no gráfico da Figura 3, em termos de frequência relativa. No que respeita à complexidade dos conhecimentos científicos, os dados mostram que as questões de trabalho prático de ambas as modalidades de fichas de avaliação externa avaliam conhecimento científico sobretudo de grau 2, correspondente a conceitos simples. Os graus 1 e 4 (factos e temas unificadores, respectivamente) estão ausentes nesta avaliação de trabalho prático.

Os resultados expressos no gráfico da Figura 3 evidenciam que, em ambas as fichas de avaliação externa, as questões de trabalho prático avaliam capacidades cognitivas que implicam, sobretudo, o processo cognitivo de compreensão (grau 2). Também é possível constatar que as capacidades cognitivas avaliadas nas questões de trabalho prático dos exames nacionais apresentam algumas diferenças quanto ao seu grau de complexidade quando comparadas com as capacidades cognitivas dos testes intermédios. Nessas segundas fichas de avaliação externa, para além de não existirem questões de trabalho prático classificadas com o grau 4, existem questões classificadas com o grau 1 . No entanto, o balanço entre as capacidades cognitivas simples (graus 1 e 2) e as capacidades complexas (graus 3 e 4) é muito próximo nas duas modalidades de fichas (respectivamente 


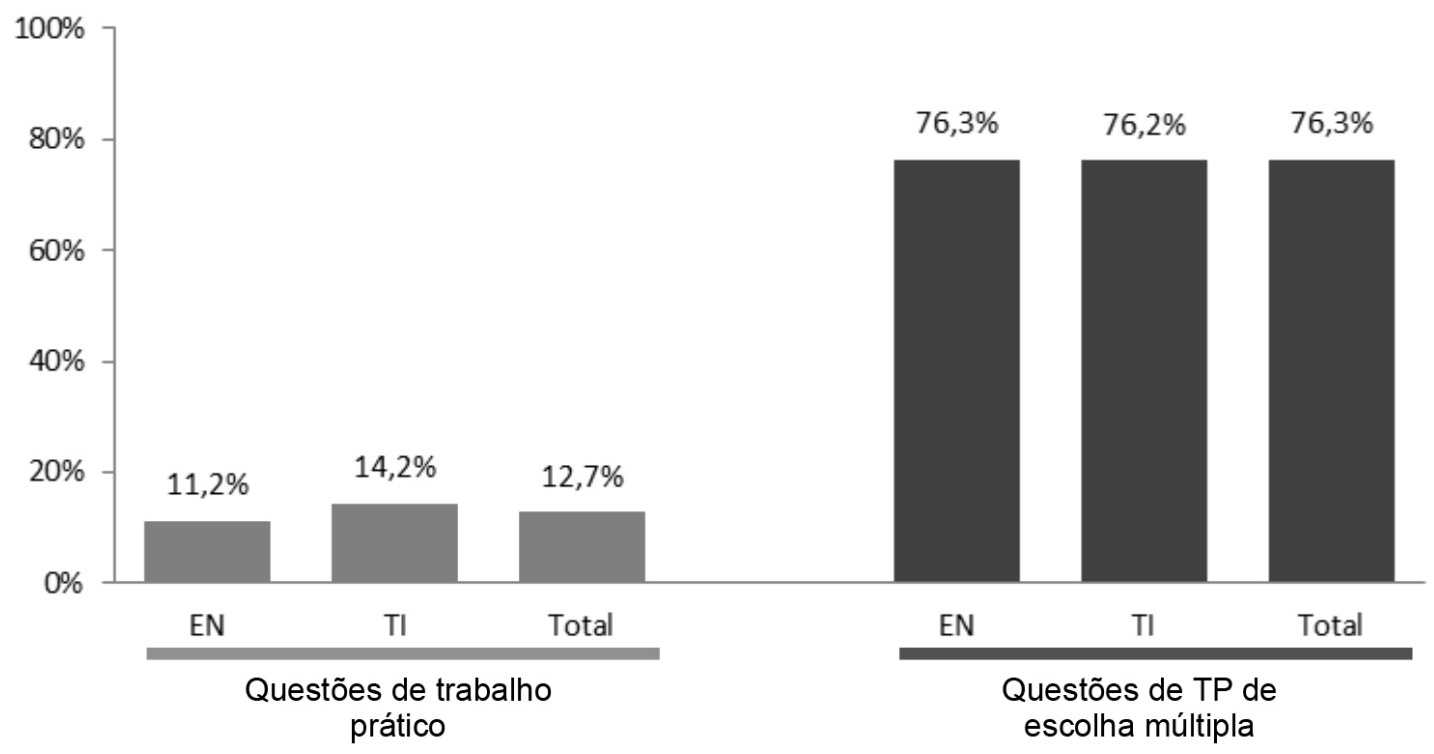

Figura 2. Questões de avaliação de trabalho prático e questões de trabalho prático (TP) de escolha múltipla nas fichas de avaliação externa (EN- exames nacionais; TI- testes intermédios; Total- Conjunto dos EN e TI).

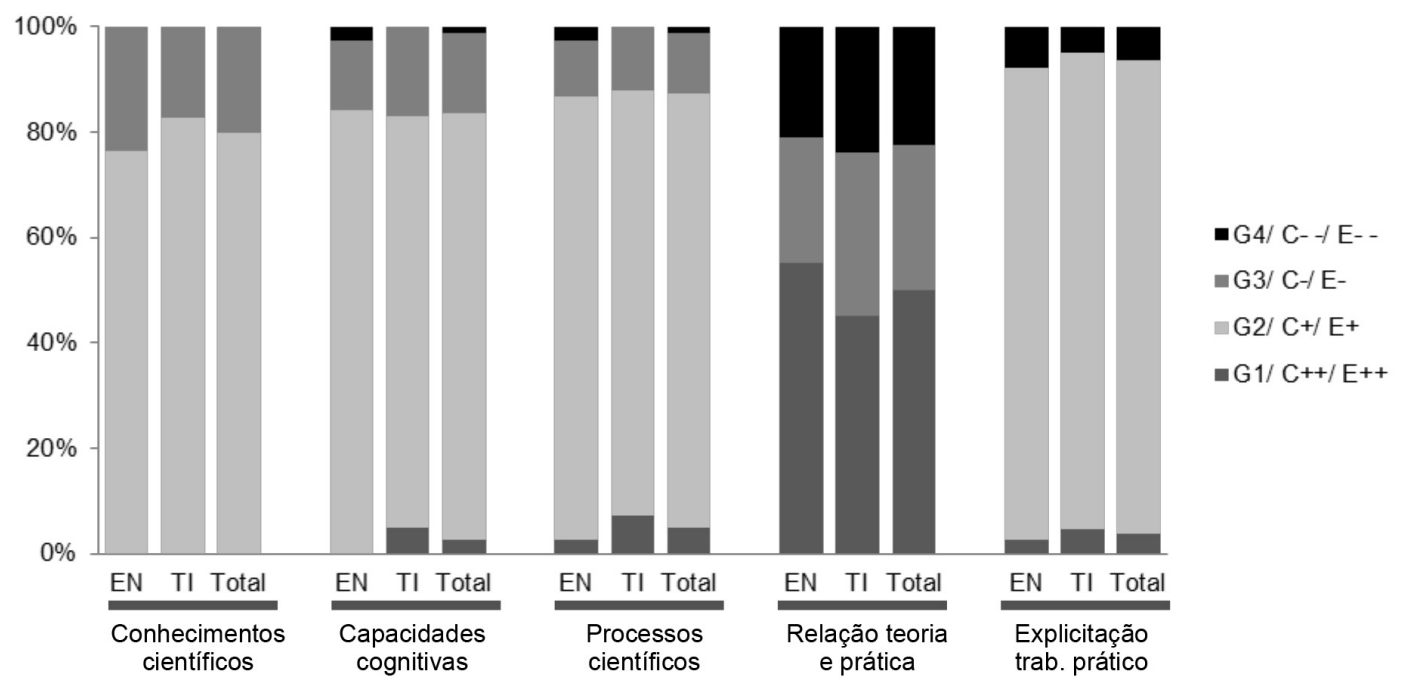

Figura 3. Dimensões relacionadas com o que se avalia e o como se avalia quanto ao trabalho prático nas fichas de avaliação externa (EN - exames nacionais; TI - testes intermédios; Total Conjunto dos EN e TI). 
de $84 \%$ e $16 \%$ nos exames nacionais e de $83 \%$ e $17 \%$ nos testes intermédios).

Dentro do grupo das capacidades cognitivas, salientam-se as capacidades de processos científicos. Na sua globalidade, a complexidade dessas capacidades é semelhante à complexidade das capacidades cognitivas gerais. Este aspecto deve-se ao facto de, na maior parte das questões de trabalho prático, a única capacidade presente ser uma capacidade de processos científicos. O excerto [10], que a seguir se transcreve, exemplifica essa situação.

Quando se comparam os resultados das capacidades cognitivas gerais com os dados relativos às capacidades de processos científicos, há ainda a destacar, nas capacidades de processos científicos, o aparecimento de questões de trabalho prático classificadas com o grau 1, quer nos exames nacionais, quer nos testes intermédios. Essa diferença na análise deve-se a questões de trabalho prático que apelam à leitura de dados expressos em gráficos ou em tabelas para a explicação de determinado acontecimento. Nesse tipo de questões, a capacidade de processos científicos é classificada com grau 1 e a capacidade cognitiva geral tem um grau de complexidade superior. O excerto [11], transcrito a seguir, ilustra essa situação.
No que diz respeito às relações intradisciplinares entre teoria e prática, os resultados da análise (Figura 3) mostram que nos exames nacionais predominam as questões de trabalho prático classificadas com o grau $\mathrm{C}^{++}$(55\%). Esse grau continua a receber uma grande ênfase nos testes intermédios (45\%). Tal classificação refere-se à segunda parte do descritor, ou seja, essas questões contemplam apenas conhecimento processual. $\mathrm{O}$ excerto [10] exemplifica a situação. Note-se que essa questão pretende apenas avaliar o conhecimento relativo ao controlo de variáveis numa determinada investigação, sem o relacionar com conhecimento declarativo. Comparando os exames nacionais com os testes intermédios, nos segundos verifica-se um ligeiro aumento dos graus que refletem uma relação entre os dois tipos de conhecimento ( $\mathrm{C}^{-}$e $\mathrm{C}^{-}$), nomeadamente a relação em que o conhecimento declarativo tem maior estatuto (grau C-).

Quando se considera a relação MECprofessor no que se refere à explicitação da avaliação do trabalho prático, é possível verificar que a mensagem, quer dos exames nacionais quer dos testes intermédios, revela uma grande preocupação com a explicitação dos conhecimentos científicos que são objeto de avaliação no trabalho prático. De facto,

\section{GRUPO IV \\ [...] \\ 1. Selecione a alternativa que completa a frase seguinte, de modo a obter uma afirmação correta. \\ Para que os resultados desta experiência permitam estabelecer conclusões válidas, os ratos do grupo A devem ter sido...}

[10] (A) ...injetados com maior número de células tumorais do que os do grupo B.

(B) ...submetidos a um ambiente com mais oxigénio do que os do grupo B.

(C) ... selecionados com a mesma idade e o mesmo sexo que os do grupo B.

(D) ...injetados numa região corporal diferente da do grupo B.

Proposta de correção do MEC - Opção C.

(Teste Intermédio de Maio de 2008, $11^{\circ}$ ano)

Olhar de professor, Ponta Grossa, 16(1): 149-172, 2013. 


\section{I}

\section{Recifes de coral}

[...]

3. Quando, em laboratório, se procedeu à análise das rochas vulcânicas recolhidas nas sondagens efetuadas no atol de Eniwetok, questionou-se a proveniência de uma amostra. O quadro I apresenta a composição química da mesma.

Quadro I

\begin{tabular}{|c|c|c|c|c|c|c|c|c|c|c|}
\hline \multicolumn{10}{|c|}{ Composição química (\% óxidos) } \\
\hline $\mathrm{SiO}_{2}$ & $\mathrm{Al}_{2} \mathrm{O}_{3}$ & $\mathrm{Fe}_{2} \mathrm{O}_{3}$ & $\mathrm{FeO}$ & $\mathrm{MgO}$ & $\mathrm{CaO}$ & $\mathrm{Na}_{2} \mathrm{O}_{3}$ & $\mathrm{~K}_{2} \mathrm{O}$ & $\mathrm{P}_{2} \mathrm{O}_{5}$ & $\mathrm{H}_{2} \mathrm{O}^{-}$ & Outros \\
\hline 74,2 & 14,7 & 0,3 & 0,8 & 0,1 & 0,8 & 3,9 & 4,0 & 0,3 & 0,7 & 0,4 \\
\hline
\end{tabular}

Explique de que modo a análise da composição química da amostra mencionada pode ter contribuído para pôr em causa a sua proveniência.

Proposta de correção do MEC - A resposta deve contemplar os seguintes tópicos:

- sendo o atol edificado sobre vulcões com origem num ponto quente, os magmas associados são de origem mantélica;

- os magmas com origem em rochas mantélicas têm reduzidos teores em sílica;

- a elevada percentagem em sílica da amostra analisada torna improvável a sua origem em magmas mantélicos.

(Exame Nacional de 2006, $2^{\mathrm{a}}$ fase)

cerca de $90 \%$ do total de questões de avaliação de trabalho prático foram classificadas com $\mathrm{E}^{+}$(Figura 3), essencialmente referente a orientações explícitas sobre os conhecimentos científicos a avaliar e a orientações genéricas, ou ausentes, sobre as capacidades cognitivas. ${ }^{10}$ Uma pequena percentagem das questões, para além de terem orientações explícitas quanto ao conhecimento científico a avaliar (declarativo e/ou processual), também têm indicado de forma explícita a capacidade cognitiva que pretendem avaliar, tendo sido classificadas com o grau $\mathrm{E}^{++}$(ver excerto [7] no Quadro 4). É ainda importante salientar que todas as questões de trabalho prático classificadas com o grau $\mathrm{E}^{--}$(cerca de

10. $\mathrm{O}$ grau $\mathrm{E}^{+}$referente a orientações explícitas sobre as capacidades cognitivas a avaliar e a orientações genéricas (ou ausentes) sobre os conhecimentos científicos apenas foi atribuído a duas questões de trabalho prático dos exames nacionais.
$8 \%$ para os exames nacionais e de $5 \%$ para os testes intermédios) correspondem à segunda parte do descritor, ou seja, a orientações do MEC com incorreções na formulação de uma determinada questão (ver excerto [8] no Quadro 4).

\section{Discussão e conclusões}

No presente estudo, procurou-se analisar a mensagem sociológica veiculada pelo DPO das fichas de avaliação externa de Biologia e Geologia do ensino secundário (exames nacionais e testes intermédios) quanto a dimensões de $o$ que e de $o$ como se avalia quanto ao trabalho prático, de modo a apreciar o seu nível de exigência conceptual. A análise também permitiu avaliar os processos de recontextualização que podem ter ocorrido entre a mensagem 
expressa no currículo de Biologia e Geologia (FERREIRA; MORAIS, 2013) e a mensagem expressa na avaliação externa dessa disciplina. Apesar de a análise estar centrada no sistema educacional português, os instrumentos elaborados e os conceitos envolvidos também podem ser utilizados para apreciar o nível de exigência conceptual do trabalho prático na avaliação externa das ciências a nível internacional. O recurso à mesma abordagem metodológica possibilitará o estabelecimento de comparações entre eles.

Os resultados deste estudo mostram que as fichas de avaliação externa atribuem pouca ênfase ao trabalho prático na avaliação de Biologia e Geologia do ensino secundário em Portugal. Essa representação do trabalho prático ainda é menor que a existente no currículo da disciplina (FERREIRA; MORAIS, 2013). Se, por um lado, o MEC dá orientações aos professores para avaliarem a componente prática de Biologia e Geologia com um peso mínimo de 30\% (Portaria n ${ }^{\circ}$ 1322/2007), por outro, o MEC, quando implementa a avaliação externa, parece não valorizar aquela avaliação. Essas discrepâncias entre a legislação, o currículo e a avaliação externa remetem para a existência de inconsistências no sistema educativo português, que tendem a exercer um efeito perverso na prática pedagógica. Os professores tendem a dar mais atenção aos exames do que ao currículo, de tal modo que o que não é objeto de avaliação externa tende a ser ignorado na prática pedagógica (BRITTON; SCHNEIDER, 2007). Se, tal como preconiza o GAVE (2011), os instrumentos de avaliação sumativa externa são "de enorme valia para a regulação das práticas educativas", questiona-se qual a mensagem que está a ser dada aos professores pela avaliação externa do MEC.

Considerando as questões de avaliação do trabalho prático da avaliação externa, grande parte (cerca de $76 \%$ ) delas corresponde a questões de seleção de escolha múltipla. A opção por esse tipo de questão apresenta vantagens e desvantagens. Como principais vantagens, salienta-se o facto de a correção ser relativamente rápida e objetiva. Como principal desvantagem, destaca-se o facto de não haver evidências diretas das razões pelas quais os alunos escolhem determinada alternativa, podendo essa escolha ter sido feita ao acaso ou pelas razões erradas (BLACK; WILIAN, 2007; BRITTON; SCHNEIDER, 2007; HARLEN, 1999). De modo a contornar algumas das limitações apresentadas pelas questões de escolha múltipla, seria possível recorrer ao pedido de justificação de algumas das alternativas selecionadas pelo aluno. Tal como referem Pasquale e Grogan (2008, p.285), “ao pedir aos alunos para justificarem as suas respostas, torna-se evidente se a resposta foi ao acaso ou não". Noutros casos, de modo a aumentar o nível de exigência conceptual da avaliação externa, a questão de escolha múltipla poderia ser transformada numa questão de construção. Ao contrário das questões de escolha múltipla, nas questões de construção os alunos têm de possuir regras de realização ativa.

Um aspeto importante que foi realçado pela análise refere-se à maior representatividade da componente de Biologia nas fichas de avaliação externa em relação à componente de Geologia (cerca de $84 \%$ do total de questões de avaliação de trabalho prático). Esse procedimento do MEC traduz uma importante mensagem para o professor: a Biologia é a área do conhecimento com mais estatuto quando se considera o trabalho prático na disciplina de Biologia e Geologia. Essa mensagem desvia-se da mensagem do currículo (FERREIRA; MORAIS, 2013), no qual as duas áreas do conhecimento têm igual estatuto na valorização do trabalho prático. Este facto evidencia desde logo um importante processo de recontextualização oficial, 
referente ao que, no sentido da seleção dos conhecimentos relativos ao trabalho prático a serem aprendidos pelos alunos. Aquela mensagem, ao regular a prática pedagógica do professor, poderá conduzir à alocação de mais tempo à Biologia. Se de facto o MEC pretende dar mais tempo ao trabalho prático realizado no âmbito da componente de Biologia, então o currículo deveria ser alterado nesse sentido, de modo que os professores não recebessem duas mensagens divergentes.

Através da análise conjunta da complexidade dos conhecimentos científicos e das capacidades cognitivas e ainda da relação entre teoria e prática, foi possível apreciar o nível de exigência conceptual do trabalho prático avaliado nas fichas de avaliação externa. Relativamente à complexidade dos conhecimentos científicos, a avaliação externa do trabalho prático de Biologia e Geologia valoriza sobretudo conceitos simples. Há, assim, uma descontinuidade entre a mensagem do currículo quanto ao trabalho prático, uma vez que a componente de Biologia do currículo (a que tem maior representatividade nas fichas de avaliação externa) dá mais ênfase aos conhecimentos científicos complexos (conceitos complexos e temas unificadores).

Quanto à complexidade das capacidades cognitivas, onde se incluem as capacidades de processos científicos, a avaliação externa atribui maior destaque às capacidades simples, sobretudo às que implicam o processo de compreensão. À semelhança dos conhecimentos científicos, também neste caso há um desfasamento em relação à mensagem da componente de Biologia do currículo, na qual predominam as capacidades complexas, principalmente aquelas associadas ao processo cognitivo de análise. No caso concreto das capacidades de processos científicos, algumas dessas capacidades (por exemplo, as ligadas à execução de trabalho laboratorial investigativo) não podem ser avaliadas com recurso a um exame escrito, tendo de ser avaliadas por meio de um exame prático. Contudo, como a realização de exames práticos a nível nacional encontra dificuldades organizacionais de várias ordens, as atuais fichas de avaliação externa deveriam compensar essa lacuna estrutural com uma maior focagem em capacidades de processos científicos de nível elevado, em vez de se centrarem fundamentalmente em capacidades de nível baixo.

No que concerne à relação entre teoria e prática, também se verifica uma desvalorização dessa relação quando se passa do currículo de Biologia e Geologia para as fichas de avaliação externa. Enquanto na componente de Biologia do currículo predomina a existência de uma relação entre teoria e prática, na avaliação externa metade das questões de trabalho prático contemplam apenas conhecimento processual, sem o relacionarem com o conhecimento declarativo. Pode assim verificar-se que a avaliação externa do trabalho prático vem reforçar as práticas dos professores descritas nos estudos de Seixas (2007) e Abrahams e Millar (2008). Esses autores constataram que os professores, quando implementam atividades práticas, sobretudo laboratoriais, separam a teoria e a prática.

Perante estes resultados, pode-se afirmar que a avaliação externa apresenta um baixo nível de exigência conceptual, ainda menor que o do currículo de Biologia e Geologia. São resultados preocupantes, na medida em que é a avaliação externa, e não o currículo, que tende a condicionar a prática do professor. Os resultados do estudo de Saldanha e Neves (2007), realizado no âmbito da reforma anterior (planos de estudo criados pelo Decreto-Lei no 286/89), já revelavam que o nível de exigência conceptual expresso no currículo é mais elevado do que aquele que é requerido no exame e que é o exame que dita fundamentalmente as regras 
que orientam a recontextualização expressa nas práticas dos professores, no sentido de uma diminuição do nível de exigência conceptual ao longo do ensino secundário. Esse é apenas um dos muitos aspectos em que a reforma atual não introduziu avanços (em muitos aspectos, chegou a introduzir retrocessos). Esses resultados apontam para a necessidade de se repensar a avaliação externa de Biologia e Geologia, de modo a haver uma coerência horizontal entre o currículo, a prática pedagógica e a avaliação. Tal como referem Wilson e Bertenthal (2006, p.4), "para desempenhar bem a sua função, a avaliação deve estar fortemente ligada ao currículo e à instrução para que os três elementos estejam direcionados para os mesmos objetivos”.

Relativamente à explicitação da avaliação do trabalho prático nas fichas de avaliação externa, o MEC deixa explícitos apenas os conhecimentos científicos que são objeto de avaliação. Seria para se repensar a apresentação dos critérios de correção elaborados pelo GAVE de modo a tornar também explícitas as capacidades cognitivas que se pretendem avaliar em cada questão. Essa explicitação, em conjunto com o aumento do grau de complexidade dessas capacidades, poderia promover a implementação de trabalho prático nas aulas de ciências do ensino secundário. Há a ainda a destacar que o GAVE, ao elaborar as questões de avaliação de trabalho prático, descura por vezes o seu rigor científico. Um exame nacional, com funções de certificação e de seleção no acesso ao ensino superior, não deve apresentar questões formuladas de forma incorreta. Tal como também não deve apresentar indicações de correção com lacunas/incorreções.

As dimensões estudadas são essenciais para inferir a influência que o DPO veiculado nas fichas de avaliação externa poderá ter na aprendizagem científica de todos os alunos. Perante os resultados deste estudo, é legítimo pensar que o nível de proficiência científica alcançado pelos alunos que recebam uma prática pedagógica baseada na avaliação externa analisada será baixo. Isso não se verificará se os professores forem capazes e estiverem motivados para recontextualizar a avaliação externa na direção certa, ou seja, no sentido de aumentar a ênfase na transmissão e na avaliação do trabalho prático, nomeadamente trabalho laboratorial, e o respetivo nível de exigência conceptual.

Os métodos de análise utilizados no estudo têm o potencial de salientar o nível de exigência conceptual das fichas de avaliação externa, em termos de dimensões de $o$ que e de como da avaliação do trabalho prático. A discriminação das diversas dimensões do trabalho prático com base em conceitos das áreas da psicologia e da sociologia permitiu uma análise detalhada das fichas de avaliação externa. Os instrumentos construídos podem ser usados em outros estudos após a sua adaptação ao respetivo contexto.

\section{Agradecimentos}

As autoras agradecem a Isabel Neves pelo seu contributo na análise das fichas de avaliação externa e na revisão do artigo. Este estudo foi financiado pela Fundação para a Ciência e Tecnologia.

\section{Referências}

ABRAHAMS, I. Practical work in secondary science: a minds-on approach. Londres: Continuum, 2011.

ABRAHAMS, I.; MILLAR, R. Does practical work really work?: a study of the effectiveness of practical work as a teaching and learning method in school science. International Journal of Science Education, v.30, n.14, p.1945-1969, 2008. 
BERNSTEIN, B. Class, codes and control: volume IV, the structuring of pedagogic discourse. Londres: Routledge, 1990.

BERNSTEIN, B. Pedagogy, symbolic control and identity: theory, research, critique. Londres: Rowman \& Littlefield, 2000.

BLACK, P.; WILIAM, D. Large-scale assessment systems: design principles drawn from international comparisons. Measurement: Interdisciplinary Research \& Perspective, v.5, n.1, p.1-53, 2007.

BRANDWEIN, P.; WATSON, F.; BLACKWOOD, P. Teaching high cchool science: a book of methods. Nova York: Harcourt Brace Jovanovich, 1958.

BRANDWEIN, P.; COOPER, E.; BLACKWOOD, P.; COTTOM-WINSLOW, M.; BOESCHEN, J.; GIDDINGS, M.; ROMERO, F.; CARIN, A. Concepts in science: teacher's edition. Nova York: Harcourt Brace Jovanovich, 1980.

BRITTON, E.; SCHNEIDER, S. Largescale assessments in science education. In: LEDERMAN, N.; ABEL, S. (Eds.). Handbook of research on science education. Mahwah, NJ: Lawrence Erlbaum, 2007, p.1007-40.

CALADO, S., NEVES, I.; MORAIS, A. Conceptual demand of science curricula: a study at the middle school level. Pedagogies: An International Journal, v.8, n.3, p.255-77, 2013.

CANTU, L. L.; HERRON, J. D. Concrete and formal piagetian stages and science concept attainment. Journal of Research in Science Teaching, v.15, n.2, p.135-143, 1978.

CHI, M.; OHLSSON, S. Complex declarative learning. In: HOLYOAK, K. J.; MORRISIN, R. G. (Eds.). Cambridge handbook of thinking and reasoning. Nova York: Cambridge University Press, 2005, p.371-99.
CRESWELL, J. W. Research design: qualitative, quantitative and mixed approaches. 2. ed. Thousand Oaks, CA: Sage, 2003.

CRESWELL, J. W.; CLARK, V. L. Designing and conduction mixed methods research. 2 . ed. California: Sage Publications, 2011.

Decreto-Lei no²86/89, de 29 de Agosto, Ministério da Educação. Diário da República, 198, I Série, 3638-3644.

Decreto-Lei n. ${ }^{074 / 2004, ~ d e ~} 26$ de Março, Ministério da Educação. Diário da República, 73, Série I-A, 1931-1942.

Decreto-Lei nº125/2011, de 29 de Dezembro, Ministério da Educação e Ciência. Diário da República, 249, $1^{\text {a }}$ série, 5498-5508.

DUSCHL, R.; SCHWEINGRUBER, H.; SHOUSE, A. (Ed.). Taking science to school: learning and teaching science in grade K-8. Washington: National Academies Press, 2007.

FERREIRA, S.; MORAIS, A. M. The nature of science in science curricula: methods and concepts of analysis. International Journal of Science Education. DOI:10.1080/09500 693.2011.621982, 2011.

FERREIRA, S.; MORAIS, A. M. Conceptual demand of practical work in science curricula: a methodological approach. Research in Science Education, 2013. DOI: 10.1007/ s11165-013-9377-7.

GAVE - Gabinete de Avaliação Educacional (2010a). Testes intermédios. Lisboa: Ministério da Educação, 2010a. Disponível em: $<$ http://www.gave.min-edu.pt/np3/9.html $>$. Acesso em: 30 ago. 2010.

GAVE - Gabinete de Avaliação Educacional. Informação $n^{0}$ 07.11. Lisboa: Ministério da Educação, 2010b.

GAVE - Gabinete de Avaliação Educacional. Exames nacionais do Ensino Secundário. 
Lisboa: Ministério da Educação, 2011. Disponível em: <http://www.gave.min-edu.pt/ np3/39.html>. Acesso em: 5 jan. 2011.

HARLEN, W. Purpose and procedures for assessing science process skills. Assessment in Education, v.6, p.129-44, 1999.

HODSON, D. Re-thinking old says: towards a more critical approach to practical work in school science. Studies in Science Education, v.22, n.1, p.85-142, 1993.

HOFSTEIN, A.; LUNETTA, V. The laboratory in science education: foundations for the twenty-first century. Science Education, v.88, p.28-54, 2004.

LUNETTA, V.; HOFSTEIN, A.; CLOUGH, $M$. Learning and teaching in the school science laboratory: an analysis of research, theory, and practice. In: LEDERMAN, N.; ABEL, S. (Eds.). Handbook of Research on Science Education. Mahwah, NJ: Lawrence Erlbaum, 2007, p.393-441.

MILLAR, R.; MARECHAL, J. F.; TIBERGHIEN, A. Maping the domain: varieties of practical work. In: J. LEACH, J.; PAULSEN, A. (Eds.). Practical work in science education. Dinamarca: Roskilde University Press, 1999, p.33-59.

MORAIS, A. M. Influência do nível de exigência conceptual dos professores no sucesso dos alunos em ciências: um estudo sociológico. Revista de Educação, v.II, n.1, p.62-80, 1991.

MORAIS, A. M.; NEVES, I. Pedagogic Social Contexts: Studies for a Sociological of Learning. In: MORAIS, A.; NEVES, I.; DAVIES, B.; DANIELS, H. (Eds.). Towards a sociology of pedagogy: the contribution of Basil Bernstein to research. Nova York: Peter Lang, 2001, p.185-221.

MORAIS, A. M.; NEVES, I. P.; PIRES, D. The what and the how of teaching and lear- ning: going deeper into sociological analysis and intervention. In: MULLER, J.; DAVIES, B.; MORAIS, A. (Eds.). Reading Bernstein, researching Bernstein. Londres: Routledge \& Falmer, 2004, p.75-90.

MORAIS, A. M.; NEVES, I. P. Basil Bernstein as an inspiration for educational research: specific methodological approaches. In: SINGH, P.; SADOVNIK A.; SEMEL, S. (Eds.). Tool Kits, translation devices and conceptual accounts: essays on Basil Bernstein's sociology of knowledge. Nova York: Peter Lang, 2010, p.11-32.

MORAIS, A. M.; NEVES, I. Educational texts and contexts that work: discussing the optimization of a model of pedagogic practice. In: FRANDJI, D.; VITALE, P. (Eds.). Knowledge, pedagogy \& society: international perspectives on Basil Bernstein's sociology of education. Londres: Routledge, 2011, 191-207.

MARZANO, R. J.; KENDALL, J. S. The new taxonomy of educational objective. 2. ed. Thousand Oaks, CA: Corwin Press, 2007.

MARZANO, R. J.; KENDALL, J. S. Designing \& assessing educational objectives: applying the new taxonomy. Thousand Oaks, CA: Corwin Press, 2008.

PASQUALE, M.; GROGAN, M. Aligning classroom-based assessment with highstakes tests. In: COFFEY, J.; DOUGLAS, R.; STEARNS, C. (Eds.). Assessing science learning: perspectives from research and practice. Washington, DC: NSTA Press, 2008, p.283-99.

PELLA, M.; VOELKER, A. Teaching the concepts of physical and chemical change to elementary school children. Journal of Research in Science Teaching, v.5, p.311-23, 1968.

Olhar de professor, Ponta Grossa, 16(1): 149-172, 2013. Disponível em <http://www.uepg.br/olhardeprofessor> 
Portaria n. ${ }^{\circ}$ 1322/2007, de 4 de Outubro, Ministério da Educação. Diário da República, $1^{\mathrm{a}}$ série, 192, 7107-7123.

ROBERTS, R.; GOTT, R.; GLAESSER, J. Students' approaches to open-ended science investigation: the importance of substantive and procedural understanding. Research Papers in Education, v.25, n.4, p.377-407, 2010.

SALDANHA, A.; NEVES, I. Influência dos exames na recontextualização dos programas: um estudo centrado na biologia do ensino secundário. Revista de Educação, v.XV, n.1, p.47-66, 2007.

SEIXAS, P. Relação teoria-prática nas aulas de biologia e geologia do $10^{\circ}$ ano de escolaridade: um estudo no contexto da actual reforma curricular. Tese de Mestrado, Faculdade de Ciências da Universidade de Lisboa, 2007.

WILSON, M.; BERTENTHAL, M. (Eds.). Systems for state science assessment. Washington, DC: National Academies Press, 2006.

Enviado em:02/06/2013

Aceito em:18/07/2013 